\title{
The History of Parkinson's Disease: Early Clinical Descriptions and Neurological Therapies
}

\author{
Christopher G. Goetz \\ Department of Neurological Sciences and Department of Pharmacology, Rush University \\ Medical Center, Chicago, Illinois 60612 \\ Correspondence: cgoetz@rush.edu
}

\begin{abstract}
Although components of possible Parkinson's disease can be found in very early documents, the first clear medical description was written in 1817 by James Parkinson. In the mid-1800s, Jean-Martin Charcot was particularly influential in refining and expanding this early description and in disseminating information internationally about Parkinson's disease. He separated Parkinson's disease from multiple sclerosis and other disorders characterized by tremor, and he recognized cases that later would likely be classified among the Parkinsonism-plus syndromes. Early treatments of Parkinson's disease were based on empirical observation, and anticholinergic drugs were used as early as the nineteenth century. The discovery of dopaminergic deficits in Parkinson's disease and the synthetic pathway of dopamine led to the first human trials of levodopa. Further historically important anatomical, biochemical, and physiological studies identified additional pharmacological and neurosurgical targets for Parkinson's disease and allow modern clinicians to offer an array of therapies aimed at improving function in this still incurable disease.
\end{abstract}

\begin{abstract}
mportant historical anchors for the study of Parkinson's disease concern the early descriptions of the disorder, its separation from other neurological conditions, and the evolution of therapy from empirical observations to rational treatment designs based on the growing knowledge of anatomy, biochemistry, and physiology of the basal ganglia. Whereas the rest of this collection will focus on the contemporary and future directions of these issues, this article provides the background history of Parkinson's disease, highlighting persons and discoveries primarily from the nineteenth and early twentieth centuries.
\end{abstract}

\section{EARLY CLINICAL DESCRIPTIONS}

\section{Defining Parkinson's Disease}

Parkinson's disease was first medically described as a neurological syndrome by James Parkinson in 1817, though fragments of Parkinsonism can be found in earlier descriptions (Parkinson 1817). As examples, Sylvius de la Boë wrote of rest tremor, and Sauvages described festination (Sylvius de la Boë 1680; Sauvages 1768; Tyler 1992). Much earlier, traditional Indian texts from approximately $1000 \mathrm{BC}$ and ancient Chinese sources also provide descriptions that suggest Parkinson's disease (Manyam 1990;

Editor: Serge Przedborski

Additional Perspectives on Parkinson's Disease available at www.perspectivesinmedicine.org

Copyright (C) 2011 Cold Spring Harbor Laboratory Press; all rights reserved; doi: 10.1101/cshperspect.a008862

Cite this article as Cold Spring Harb Perspect Med 2011;1:a008862 
C.G. Goetz

Zhang et al. 2006). In succinct and pithy English, Parkinson captured the clinical picture:

Involuntary tremulous motion, with lessened muscular power, in parts not in action and even when supported; with a propensity to bend the trunk forward, and to pass from a walking to a running pace: the senses and intellects being uninjured.

Parkinson reported on six case sketches, three of the patients observed in the streets of London and one only seen from a distance (Fig. 1).

Jean-Martin Charcot, in his teaching at the Salpêtrière over 50 years later, was more thorough in his descriptions and distinguished bradykinesia as a separate cardinal feature of the illness (Charcot 1872):

Long before rigidity actually develops, patients have significant difficulty performing ordinary activities: this problem relates to another cause. In some of the various patients I showed you, you can easily recognize how difficult it is for them to do things even though rigidity or tremor is not the limiting feature. Instead, even a cursory exam demonstrates that their problem relates more to slowness in execution of movement rather than to real weakness. In spite of tremor, a patient is still able to do most things, but he performs them with remarkable slowness. Between the thought and the action there is a considerable time lapse. One would think neural activity can only be effected after remarkable effort.

Charcot and his students described the clinical spectrum of this disease, noting two prototypes, the tremorous and the rigid/akinetic form. They described in full detail the arthritic changes, dysautonomia, and pain that can accompany Parkinson's disease. Charcot was also the first to suggest the use of the term "Parkinson's disease" rejecting the earlier designation of paralysis agitans or shaking palsy, because he recognized that Parkinson's disease patients are not markedly weak and do not necessarily have tremor (Charcot 1872).

William Gowers, working in London, contributed an important study of Parkinson's disease demographics in his "Manual of Diseases of the Nervous System," describing his personal experience with 80 patients in the 1880s. He correctly identified the slight male predominance of the disorder and studied the joint deformities typical of the disease. Known for his descriptive prose, Gowers offered one of the most memorable similes regarding Parkinsonian tremor (Gowers 1888):

The movement of the fingers at the metacarpalphalangeal joints is similar to that by which Orientals beat their small drums.

Further clinical descriptions and studies of the pathologic changes related to Parkinson's disease were predominantly reported by the French neurologic school. Richer and Meige (1895) provided clinical and morphologic details of the progressive stages of Parkinsonian disability, and the former provided drawings and statues that remain among the most important pictorial documents related to Parkinson's disease. Babinski commented on the strange motor fluctuations intrinsic to the disease itself (Babinski 1921). Brissaud first proposed damage to the substantia nigra as the anatomical seat of Parkinson's disease, and Trétiakoff and Foix and Nicolesco pursued further pathologic studies of the midbrain in relationship to the disease during the 1920s (Trétiakoff 1921; Brissaud 1925; Foix and Nicolesco 1925).

The most complete pathologic analysis of Parkinson's disease and the clear delineation of the brain stem lesions was performed in 1953 by Greenfield and Bosanquet (Greenfield and Bosanquet 1953). The morbidity and clinical progression of Parkinson's disease was studied in the important article by Hoehn and Yahr in which their internationally recognized staging system was first introduced. This timehonored staging system is anchored in the distinction between unilateral (Stage I) disease and bilateral disease (Stages II-V) and the development of postural reflex impairment (Stage III) as a key turning point in the disease's clinical significance (Hoehn and Yahr 1967).

\section{Separating Parkinson's Disease from Other Disorders}

Prior to Charcot, the classification system, or nosology, of neurological disease was primitive, and disorders were largely grouped by primary symptoms, for instance, tremors or weakness. 


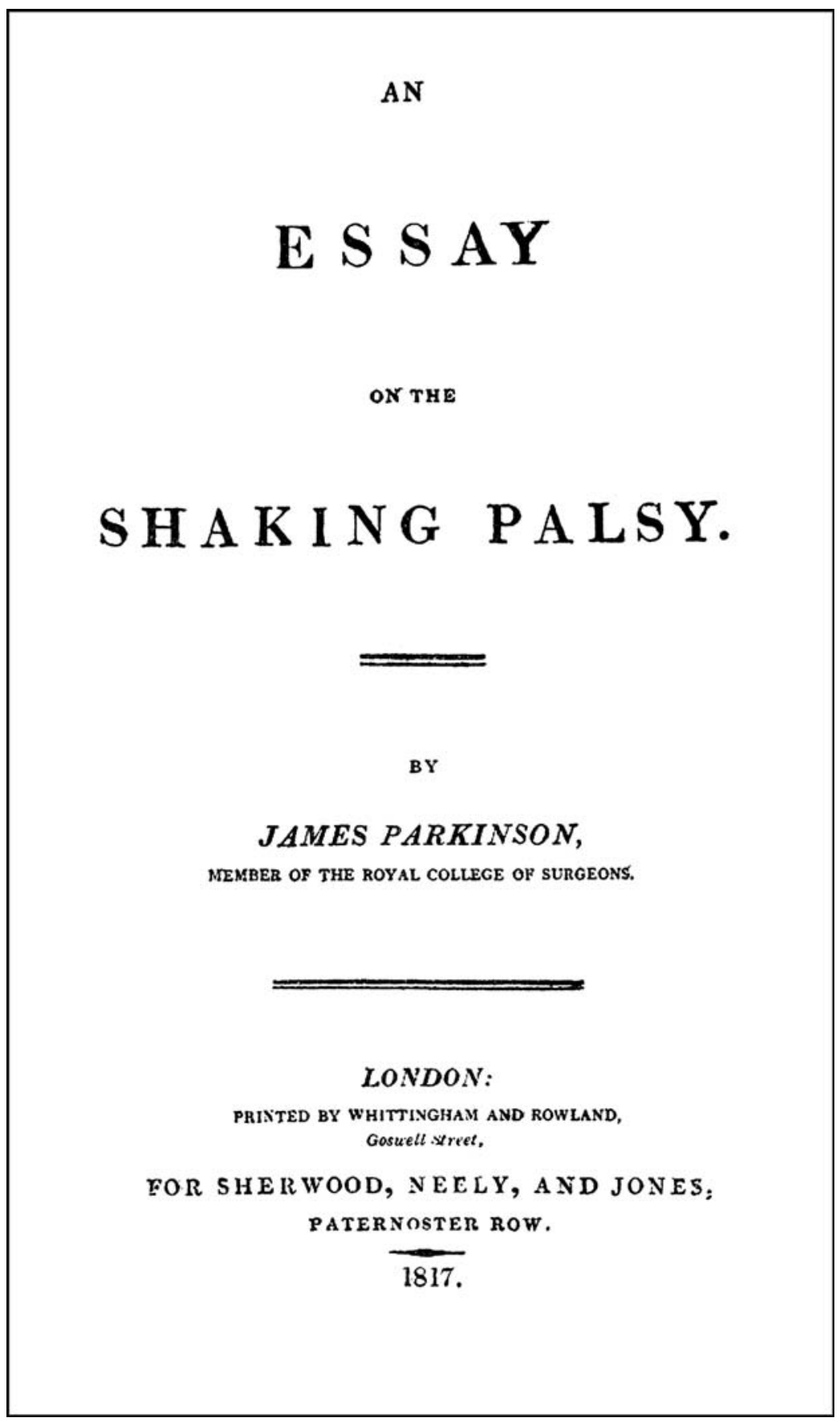

Figure 1. Essay on the Shaking Palsy. James Parkinson's short monograph is the first clear medical document dealing with Parkinson's disease (Parkinson 1817). 


\section{C.G. Goetz}

Charcot's first important contribution to the study of Parkinson's disease was his differentiation of this disorder from other tremorous disorders, specifically multiple sclerosis (Charcot 1872). Examining large numbers of patients within the vast Salpêtrière Hospital in Paris, he developed a protocol to observe tremor at rest and then during action. He noted that the patients with action tremor had accompanying features of weakness, spasticity, and visual disturbance. In contrast, those with rest tremor differed in having rigidity, slowed movements, a typical hunched posture, and very soft speech. His early tremor studies were highly publicized and helped to establish Parkinson's disease as a distinct neurological entity that could be confidently diagnosed (Fig. 2).

Once the archetype of Parkinson's disease was established, Charcot and his students identified variants with features that were atypical of classical Parkinson's disease. These were termed Parkinson's disease without tremor, Parkinson's disease with extended posture, and Parkinson's disease with hemiplegia. These cases are of historical interest, because they are likely examples of disorders that would later be grouped under the term, Parkinsonism-plus syndromes, including progressive supranuclear palsy, corticobasal degeneration, and multiple system atrophy. As one example, Charcot presented a patient named Bachère on several occasions. On June 12, 1888, Charcot emphasized that Bachère did not have marked tremor, and in contrast to the usual arm flexion of typical Parkinson's disease, he had a stiff and extended posture.

Look how he stands. I present him in profile so you can see the inclination of the head and trunk, well described by Parkinson. All this is typical. What is atypical, however, is that Bachère's

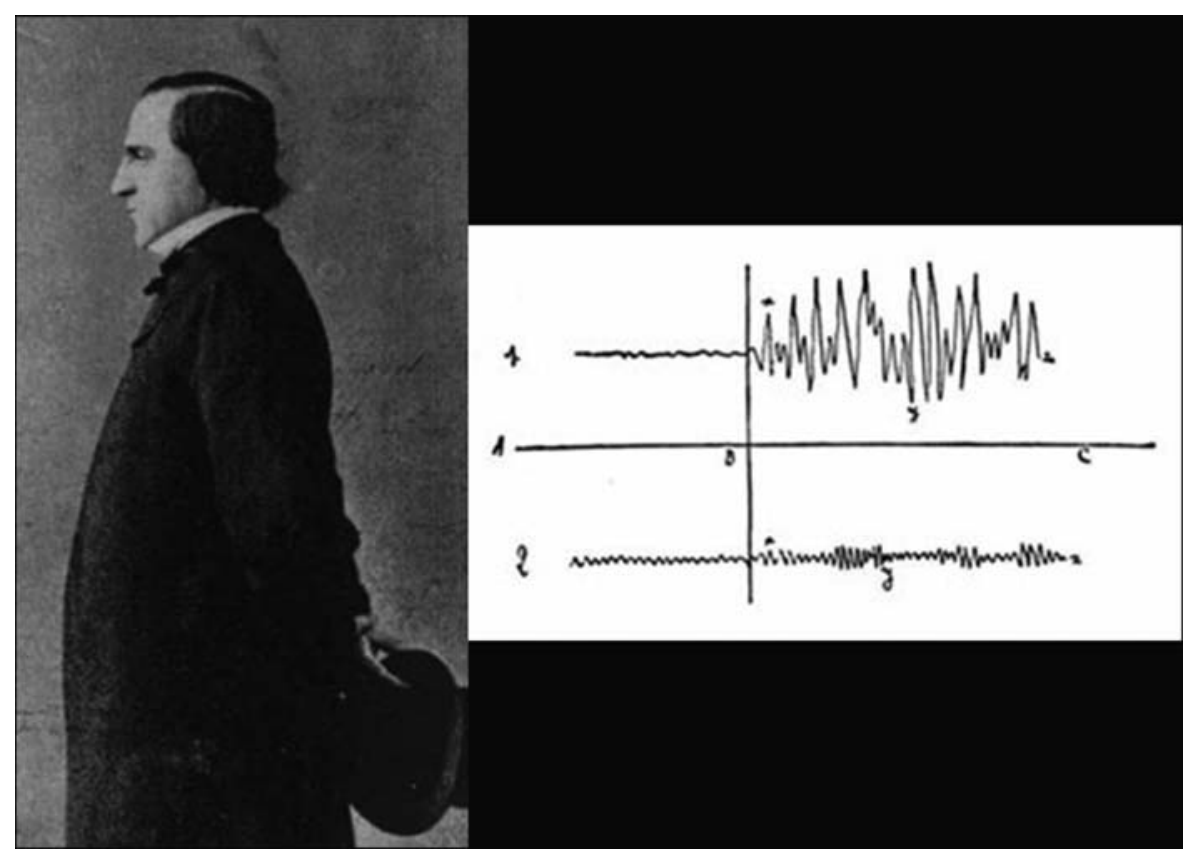

Figure 2. Charcot and "myographic curves." (Left) French neurologist Jean-Martin Charcot (1825-1893). (Right) Semi-diagrammatic "myographic curves" published by Charcot in 1887. The top tracing represents an intention tremor in multiple sclerosis. Segment AB indicates "at rest," and BC indicates increasing oscillations during voluntary movement. The lower tracing represents a Parkinsonian tremor, with segment $\mathrm{AB}$ indicating a tremor at rest, which persists in segment BC during voluntary movement. Charcot's graphical recording method on which these drawings were based is not described, but in other circumstances he relied on various pneumatic tambour-like mechanisms (Charcot 1872; Goetz 1987). 
History of Parkinson's Disease

forearms and legs are extended, making the extremities like rigid bars, whereas in the ordinary case, the same body parts are partly flexed. One can say then that in the typical case of Parkinson's disease, flexion is the predominant feature, whereas here, extension predominates and accounts for this unusual presentation. The difference is even more evident when the patients walk (Fig. 3) (Goetz 1987; Charcot 1888a).

In addition to extended posture, this patient had particular facial bradykinesia and contracted forehead muscles. Charcot commented that the patient had the perpetual look of
A

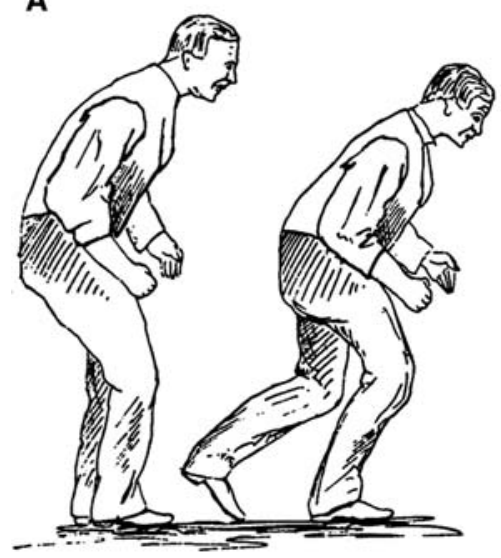

B
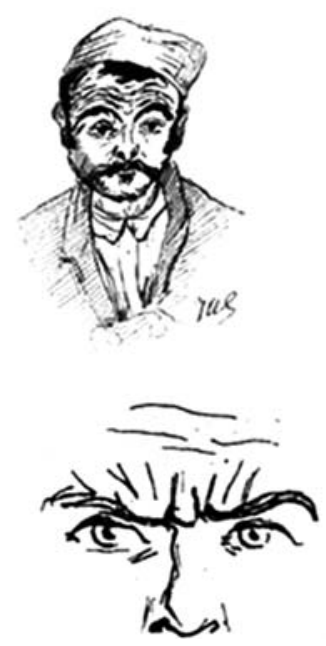
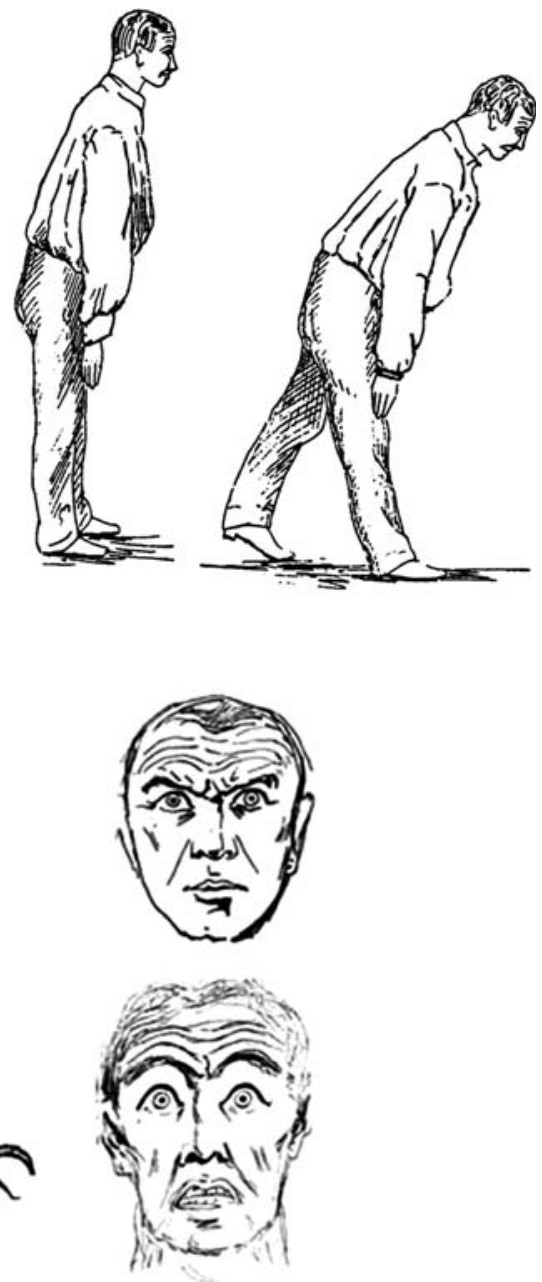

Figure 3. Atypical Parkinsonism. (A) Drawing from Charcot's original lesson, given on June 12, 1888, in which he contrasted a typical Parkinson's disease showing a flexed posture (left) with a Parkinsonian variant that included the absence of tremor and extended posture (right). Charcot regularly taught his students by comparing and contrasting cases of patients from the Salpêtrière inpatient and outpatient services. $(B)$ Four drawings by Charcot from his lesson on atypical Parkinson's disease, dated June 12, 1888, showing the distinctive facial features of his patient, Bachère, showing forehead muscles and superior orbicularis in simultaneous contraction, activation of the palpebral portion of the orbicularis and combined activation of the frontalis superior portion of the orbicularis and platysma, giving a frightened expression in contrast to the placid, blank stare of typical Parkinson's disease patients. This case is a compelling case of likely progressive supranuclear palsy (Goetz, 1987; Charcot 1888a). 
surprise, because the eyes remained widely opened and the forehead continually wrinkled (Fig. 3) (Goetz 1987; Charcot 1888a). In a modern setting, Jankovic has detailed similar facial morphology in Parkinsonism-plus patients, specifically those with progressive supranuclear palsy (Jankovic 1984). No specific supranuclear eye movement abnormalities were described. Another Salpêtrière patient with "Parkinson's disease in extension" was described by Dutil in 1889 and eye movement abnormalities are mentioned, although a supranuclear lesion is not documented clinically (Dutil 1889; Goetz 1996). This case also had highly asymmetric rigidity of the extremities, a feature more reminiscent of corticobasal degeneration than progressive supranuclear palsy. In this case, the extended neck posture was graphically emphasized:

The face is masked, the forehead wrinkled, the eyebrows raised, the eyes immobile.... This facies, associated with the extended posture of the head and trunk, gives the patient a singularly majestic air (Dutil 1889; Goetz 1996).

With clinical features reminiscent of both progressive supranuclear palsy and corticobasal degeneration, this patient was mentioned in several articles from the Salpêtrière school, although no autopsy was apparently performed. Collectively, these cases show that even the earliest diagnosticians recognized classic Parkinson's disease and cases that needed to be distinguished from it. Today, these Parkinsonism-plus diagnoses are known to have additional distinctive features, including poor response to dopaminergic therapies and different pathological lesions than seen in Parkinson's disease.

Another important entity to be distinguished from Parkinson's disease was postencephalitic Parkinsonism, today a rare cause of Parkinsonism, but a very frequent disorder in the period after 1916. Following the influenza epidemic of 1916-1917, a neurologic syndrome that included Parkinsonism, along with multiple other signs, occurred in alarming numbers (von Economo 1919). The additional behavioral, ocular, and motor problems of these patients attested to more diffuse neurologic disease than seen typically in Parkinson's disease.
This condition has largely disappeared in the twenty-first century, because the survivors have died and no recurrence of an epidemic of this magnitude has recurred. Other important forms of atypical Parkinsonism to be distinguished from Parkinson's disease include a juvenile form of Parkinson's disease, originally described by Willige in 1911 (Willige 1911), with a more full description and its association with atrophy of the globus pallidus provided by Ramsey Hunt and van Bogaert (Ramsey Hunt 1917; van Bogaert 1930).

In the years after these pioneering papers, the concepts of neural circuits evolved with key nuclei of importance to the clinical presentation of Parkinsonism being the substantia nigra, the globus pallidus, and the caudate nucleus and putamen (striatum). Involvement of the striatum resulting in Parkinsonism was documented in a variety of neurological disorders. Striatal-nigral degeneration was described by Adams, van Bogaert, and Vander Eecken, and, though originally classified as a single disease, it has since been merged into the larger diagnosis of multiple system atrophy (Adams et al. 1964). Parkinsonian states related to striatal pathology were later identified in the form of Huntington's disease, in which a Parkinsonian presentation is referred to as the Westphal variant (Westphal 1883) and in cases of striatal calcification, either on a hereditary basis (Bruyn et al. 1964) or as an acquired metabolic disorder often related to hypoparathyroidism (Muenter and Whisnant 1968).

The historical discussion of Parkinsonian disorders that are frequently confused with Parkinson"s disease includes drug-induced and toxin-induced cases as well. The introduction of the antipsychotic agents, originally termed neuroleptics, led to dramatic improvements in schizophrenic and other psychotic behaviors, but induced Parkinsonism largely indistinguishable from Parkinson's disease itself (Steck 1954). Later understanding that these drugs block dopamine receptors in the striatum explained this clinical presentation and led to the development of antipsychotic drugs with lower proclivity to block striatal receptors and less propensity to induce Parkinsonism. The 
landmark observation on a cluster of young patients who presented with severe Parkinsonism that appeared to be typical Parkinson's disease except for the young onset and severity of signs led to the discovery that the causative agent was a self-administered narcotic derivative, MPTP, that selectively damages the substantia nigra (Langston et al. 1983). This product has provided a means to induce Parkinsonism in experimental animals and remains the "gold standard" model to study Parkinson's disease in preclinical studies of new treatments for Parkinson's disease.

\section{THE EVOLUTION OF TREATMENTS}

The history of Parkinson's disease is tightly linked to therapeutic interventions, ranging from serendipitous observations to controlled clinical trials of specifically designed agents.

Parkinson devoted a chapter of his monograph to "considerations respecting the means of cure" (Parkinson 1817). In humility and perhaps with a vision toward current concepts of neuroprotection, he hoped for the identification of a treatment by which "the progress of the disease may be stopped" (Parkinson 1817). To this end, he advocated very early therapeutic intervention when signs were largely confined to the arms without balance and gait impairments. Reflecting therapeutic approaches of the early nineteenth century, Parkinson recommended venesection, specifically advocating bloodletting from the neck, followed by vesicatories to induce blistering and inflammation of the skin. Small pieces of cork were purposefully inserted into the blisters to cause a "sufficient quantity" of purulent discharge (Parkinson 1817). All these efforts were designed to divert blood and inflammatory pressure away from the brain and spinal cord, and in this way, decompress the medulla that Parkinson considered the seat of neurological dysfunction.

\section{Pharmacological Advances: Charcot and Gowers}

Being the two most celebrated clinical neurologists of the nineteenth century, Jean-Martin Charcot and William Gowers serve as important icons for the study of standard and emerging treatments for Parkinson's disease. Charcot's intern, Ordenstein, wrote his medical thesis on the treatment of Parkinsonian tremor with belladonna alkaloids, the first well-established treatment of Parkinson's disease (Ordenstein 1972). These agents are centrally active anticholinergic drugs that later would be understood to affect the cholinergic/dopaminergic balance in the striatum and thereby improve Parkinsonism. The credit of the observation of anticholinergic efficacy surely belongs to Charcot himself who managed his Salpêtrière School with strict centralized supervision and oversaw every aspect of the neurological program. As with other young and aspiring students like Gilles de la Tourette and Pierre Marie, Ordenstein profited from publishing the observation with his name as sole author, but contemporaries would not have been deluded into thinking of it as coming from anyone besides Professor Charcot. Of the many centrally active anticholinergic agents of the era, Charcot's preferred product for Parkinson's disease was hyoscyamine. This plant-based agent was prepared as pills, usually powder rolled into bits of white bread, or as a syrup. As shown in a prescription located in the Philadelphia College of Physicians, Charcot's anticholinergic treatment was sometimes combined with rye-based ergot products that in fact are the pharmacological basis of some modern dopamine agonists, drugs that directly stimulate striatal dopamine receptors and thereby simulate the activity of dopamine itself (Fig. 4). Although Tyler has aptly documented that Charcot was not the first interventionist to advocate hyoscyamine (Tyler 1992), Charcot's name became linked to the drug because of the widespread international publication of his lectures and classroom demonstrations.

A unique historical opportunity to examine the early treatment of Parkinson's disease is provided by a series of 18 unpublished letters in the Charcot collection at the Bibliothèque Charcot in Paris (Portfolio MAVIII: Parkinson's disease). These letters cover a period of at least 15 months from January 1863 through March 1864. Although the collection only contains 
C.G. Goetz
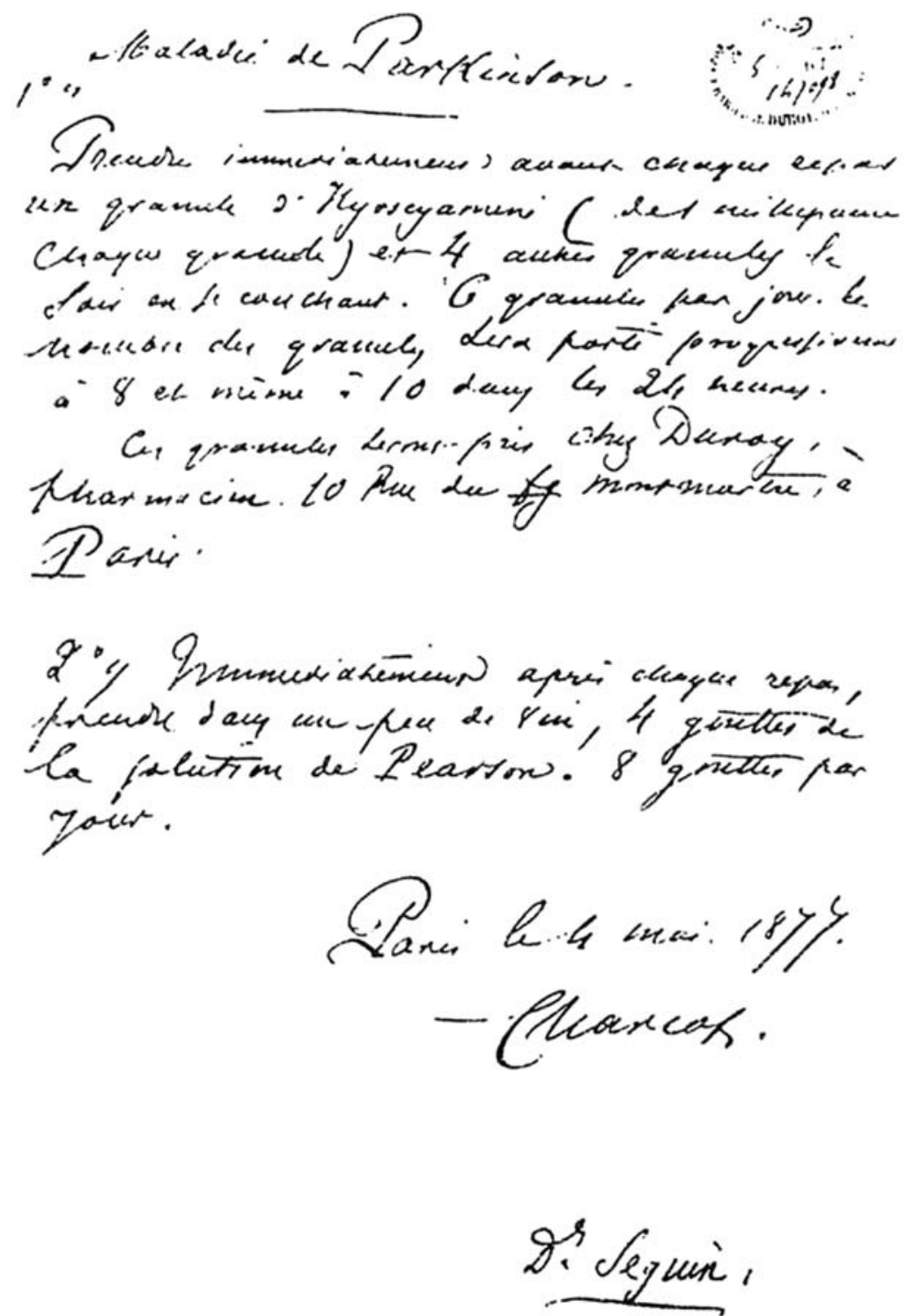

Figure 4. Early treatment of Parkinson's disease. Prescription dated 1877 from the College of Physicians of Philadelphia Library. In treating Parkinson's disease, Charcot used belladonna alkaloids (agents with potent anticholinergic properties) as well as rye-based products that had ergot activity, a feature of some currently available dopamine agonists. Charcot's advice was empiric and preceded the recognition of the well-known dopaminergic/cholinergic balance that is implicit to normal striatal neurochemical activity (Charcot 1872).

the patient's letters and not Charcot's replies, one can follow the doctor-patient interaction because of Charcot's technique of closing his letters traditionally with: "I would be most obliged Monsieur, if you would remind me of this prescription the next time you write." The patient's letters therefore systematically begin with a summary of the prescribed therapy and follow with the patient's own observations. In addition to hyoscyamine and ergot-based products, Charcot advocated an overall program of rest and reduced stress. This type of therapy 
History of Parkinson's Disease

was generally advocated for many primary neurological disorders (Mitchell 1908). For this patient, he added camphor, silver nitrate, iron compounds, henbane pills, and zinc oxide. The rationale for using these agents was not explained by Charcot, and their pharmacology does not involve the dopamine system. The use of iron may have been based on Romberg's earlier observation that carbonate of iron in association with warm baths and cold affusions to the head and back induced "a marked diminution of symptoms.” (Romberg 1846). Whether based on his own experience or Romberg's warning against trying strychnine, Charcot steered away from this therapy for Parkinson's disease patients. Charcot was highly specific in his instructions, insisting that quinquina, a quinine derivative, must be diluted with syrup made from orange rind and each dose of silver nitrate must be impregnated in $9 \mathrm{~g}$ of soft bread to form an ingestible pill. The letters communicate encouragement to the patient, reinforce the need for patience in facing chronic illness, and a willingness to consider new treatment strategies if traditional ones were unsuccessful. However, his enthusiasm to try new interventions never clouded his objective vision of efficacy. In reviewing pharmacologic treatments for Parkinson's disease in 1872, Charcot stated:
Everything, or almost everything, has been tried against this disease. Among the medicinal substances that have been extolled and which I have myself administered to no avail, I need only enumerate a few (Charcot 1872).

In rejecting most medicines, Charcot advocated vibratory therapy for the management of Parkinson's disease. Charcot had observed that after long carriage, train, or horseback rides, patients with Parkinson's disease experienced marked symptom amelioration. He therefore developed a replication device to provide rhythmic movement by an electrically powered "shaking chair" (fauteuil trépidant) (Fig. 5) (Charcot 1892a). His student, Gilles de la Tourette, fashioned a helmet that was more easily transported and vibrated the brain rather than the body (Goetz et al. 1995). Other used therapies included hydrotherapy, spa treatments, and light exercise. Electrical stimulation by faradic, galvanic, or direct spark (franklinization) therapy was used to stimulate weakened muscles. Charcot was, however, adamant that patients with Parkinson's disease were not particularly weak, having tested them with dynamometers and finding their strength to be normal for most of the duration of illness. It was partly for this reason that he dismissed the terms, paralysis agitans and shaking palsy,

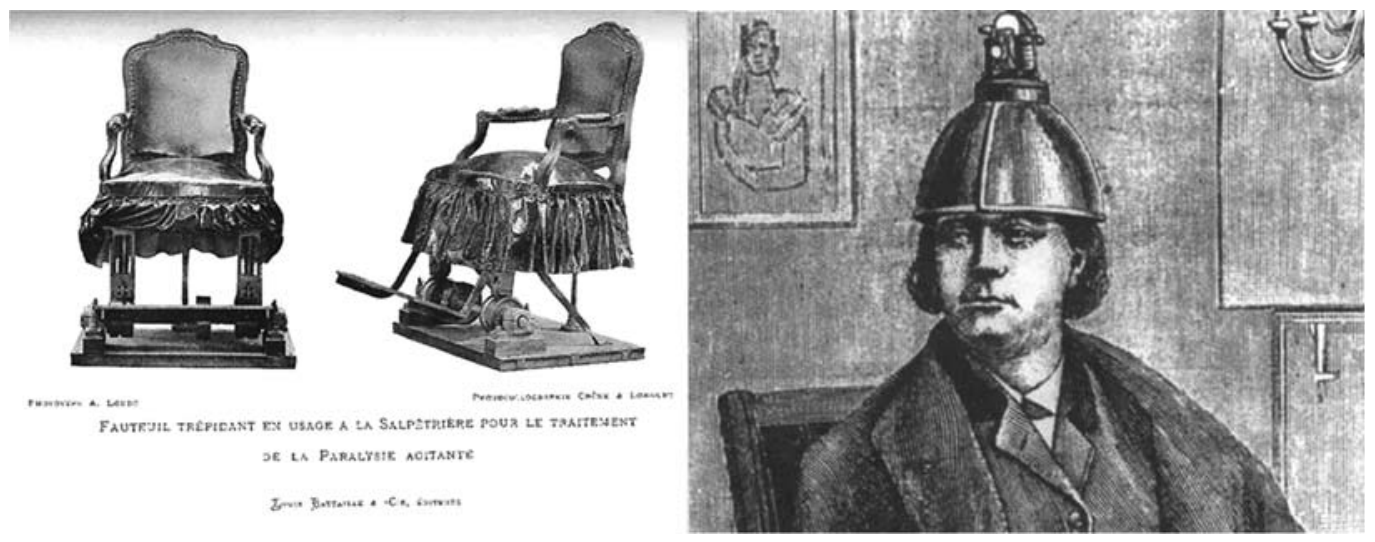

Figure 5. Vibratory therapy. Charcot observed that patients with Parkinson's disease experienced a reduction in their rest tremor after taking a carriage ride or after horseback riding. He developed a therapeutic vibratory chair that simulated the rhythmic shaking of a carriage (Goetz 1996). A vibratory helmet to shake the head and brain was later developed. Such therapies were not used widely but the availability of modern medical vibratory chairs offers an opportunity to confirm or refute Charcot's observation. 
and advocated instead the designation, Parkinson's disease.

A more unusual and hazardous early treatment of Parkinson's disease involved the use of a suspension apparatus to stretch the spinal cord (Goetz et al. 1995). Developed in 1883 in Russia, the apparatus gained celebrity when Charcot examined its safety and efficacy in a variety of disorders, including Parkinson's disease. Using gravity and the patient's weight to put excessive vertical traction on the spinal cord and nerves, the therapist hoisted the subject in mid-air with a pulley and a harness that slipped under the chin and occiput. In Parkinson's disease patients, rigidity and some sensory symptoms improved, but tremor was not ameliorated. Edmond de Goncourt described the therapy with allusions to the macabre artwork of Goya, and the serious side effects and stress on patients led Charcot to abandon this strategy shortly after its introduction in France (de Goncourt and de Goncourt 1887-1889).

Charcot's British contemporary, WR Gowers, followed similar treatment strategies. He stressed the negative effects of mental strain and physical exhaustion, advocating that "life should be quiet and regular, freed, as far as may be, from care and work." (Gowers 1899). For tremor, he used hyoscyamine and also noted arsenic, morphia, conium (hemlock), and "Indian hemp" (cannabis) as effective agents for temporary tremor abatement. Writing specifically of the power of cannabis and opium in combination, he stated: "I have several times seen a very distinct improvement for a considerable time under their use." (Gowers 1899). Today, cannabis is known to have some dopaminergic activation properties, but opium affects the motor system in a generalized, sedative manner without direct or primary dopaminergic involvement.

\section{Levodopa and Dopamine-Based Therapies}

Through the mid-twentieth century, the treatment of Parkinson's disease remained largely that of the nineteenth century, and though a wide variety of centrally active anticholinergic drugs were developed and used, they all were similar in their efficacy and side effect profiles. In the Handbook of Clinical Neurology, the chapter, "Drug treatment of parkinsonism and its assessment" (published in 1968) discusses ten synthetic anticholinergic compounds and a potpourri of agents under the designation "Other drugs which have been recommended, some of them without any justification." (Onuaguluchi 1968). The emphasis of this period remained on supportive physical therapy and the management of hypersalivation, seborrhea, decubiti, and infections. In the context of this relative stagnation, the impact of levodopa was magnified.

As summarized by Hornykiewicz, dopamine was first synthesized in 1910 by G. Barger and J. Ewens (Hornykiewicz 2002). In the same year, $H$. Dale discovered its weak sympathomimetic qualities. These observations were later remembered when P. Holtz discovered the enzyme, dopa decarboxylase and documented that levodopa was synthesized to dopamine through its action. At this time, dopamine was relegated to a simple intermediate compound for the synthesis of noradrenaline and adrenaline. The consistent identification of substantial amounts of dopamine in various tissues, however, prompted the search for a more primary role. Working in Blaschko's Cambridge University laboratory, Hornykiewicz studied blood pressure control in experimental animals and clearly confirmed that dopamine had distinct effects independent of other catecholamines. Shortly thereafter, in the late 1950s, two seminal discoveries occurred: dopamine localization within the brain, specifically in the striatum; and the development of the reserpine-model, later to be used as the first model of Parkinsonism that was reversed by levodopa treatment. In concert, these discoveries rapidly advanced hypotheses on the role of dopamine loss in the pathogenesis of Parkinson's disease itself (Carlsson et al. 1958; Sano et al. 1959), and led Bertler and Rosengred to conclude that "dopamine is concerned with the function of the striatum and thus with the control of movement." (Bertler and Rosengred 1959). Ehringer and Hornykiewicz turned to human brain and after examining a series of 
control specimens, discovered the striatal dopamine depletion in Parkinson's disease and postencephalitic parkinsonism brains (Ehringer and Hornykiewicz 1960). With the knowledge that levodopa was the natural precursor to dopamine, Hornykiewicz was now prepared to suggest human trials in Parkinson's disease patients.

Birkmayer received Hornykiewicz's supply of laboratory levodopa and injected it intravenously for the first time to Parkinsonian patients in 1961. The antiakinetic effects were quickly published:

Bed-ridden patients who were unable to sit up, patients who could not stand up when seated, and patients who when standing could not start walking performed all these activities with ease after L-dopa [levodopa]. They walked around with normal associated movements and they could even run and jump. The voiceless, aphonic speech, blurred by pallilalia and unclear articulation, became forceful and clear as in a normal person (Birkmayer and Hornykiewicz 1961).

Subsequent open-label levodopa trials with oral preparations confirmed both short and longterm benefits, and a double-blind placebo controlled trial followed (Barbeau 1969; Cotzias et al. 1969; Yahr et al. 1969). These reports launched levodopa's establishment as the premier agent to treat Parkinson's disease symptoms and signs. Although new formulations and peripherally acting dopa-decarboxylase inhibitors have added new dimensions to the therapy, none of these events rival the first discoveries.

Given that levodopa is a naturally occurring amino acid, researchers have reexamined older therapies to search for possible discoveries of levodopa-containing compounds in early medicine. Of note, cowage or cowitch plant (Mucuna pruriens) is known under the name of Atmagupta in Sanskrit and contains levodopa (Manyam 1990). One of the remedies used to treat the condition thought to be possible Parkinson's disease in traditional Indian medicine is called Masabaldi Pacana, which contains beans of Mucuna pruriens. These observations offer interesting, albeit indirect, evidence that patients with Parkinsonism may have experienced the benefit of levodopa early in the history of medicine.

The more modern discoveries of dopamine agonists and enzyme inhibitors that enhance the bioavailability of dopamine (monoamine oxidase inhibitors and catechol-O-methyl transferase inhibitors) date to the contemporary period and are of less importance to this historical review that emphasizes early discoveries. These developments have been based on the logical understanding of the dopamine system, metabolic pathways, and receptor populations. Further discoveries of modulating influences by serotonin, adenosine, GABA, and glutamate systems have opened horizons for further pharmacological developments. The history of amantadine is of interest because of its serendipitous discovery as an anti-Parkinsonian agent. Developed as an antiviral agent, it was used widely in nursing home populations, and Schwab noted its unexpected benefit on tremor, balance, and akinesia in both Parkinson's disease and postencephalitic parkinsonian patients (Schwab et al. 1969). This agent has mild dopamine effects, likely due to inhibition of striatal synaptic dopamine reuptake so that more dopamine is left within the synapse to activate dopamine receptors. It has effects on the glutaminergic system with likely indirect effects on dopamine function through this mechanism.

\section{SURGERY}

In the early 1900s, surgery for movement disorders was pioneered by V. Horsley and his engineering colleague, R.H. Clarke (Fig. 6). They developed early stereotaxic equipment to target brain nuclei, though their early surgeries dealt with hyperkinetic disorders rather than Parkinson's disease (Horsley and Clarke 1908). Bucy and Case and Klemme excised cerebral cortex to treat Parkinsonian tremor, but this type of ablative surgery induced hemiparesis and was abandoned (Bucy and Case 1939; Klemme 1940). Meyers first focused on the basal ganglia as a lesion target for abating Parkinsonian tremor in the 1940s and noted that rigidity improved as well as tremor. 


\section{C.G. Goetz}
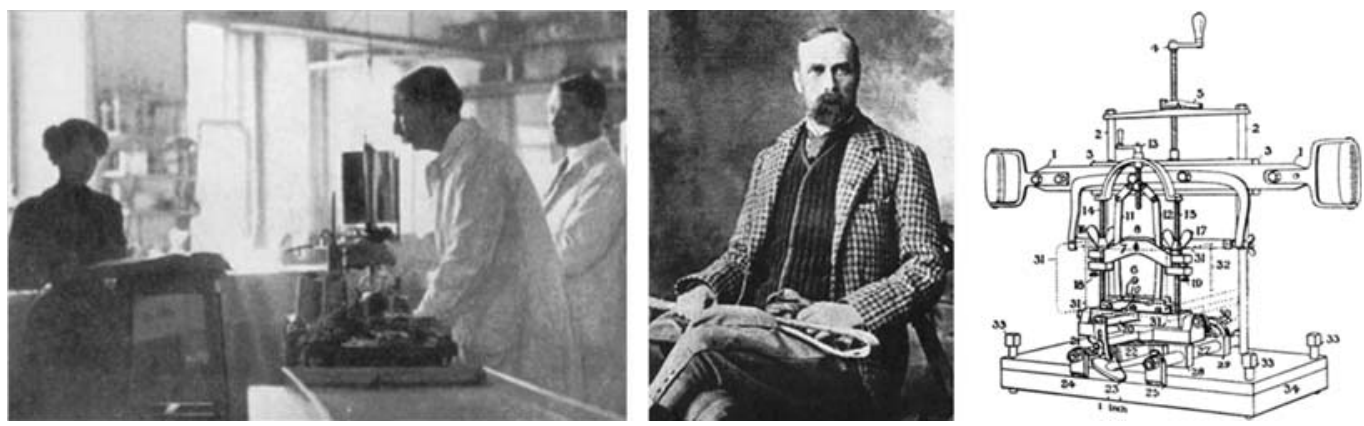

Figure 6. Early surgical interventions. (Left) Victor Horsley (1857-1916) was a celebrated British surgeon who attempted a surgical intervention on a movement disorder patient with athetosis in 1909 . He excised motor cortex with substantial improvement in involuntary movements. (Middle) Working in London with his physiologist colleague, Robert Henry Clarke (1850-1926), he developed early stereotaxic equipment, first for animal experiments and then for humans. (Right) This daunting surgical apparatus taken from their reports in Brain in 1908 guided them to deep brain centers including the basal ganglia and the cerebellum (Horsley and Clarke 1908).

Importantly, spasticity and paresis did not compromise the improvement (Meyers 1940). In 1953, by accident, I. Cooper cut the anterior choroidal artery during surgery on a Parkinsonian patient and was forced to ligate it to prevent a hematoma. The unexpected and remarkable relief of tremor and rigidity on the contralateral side led to more widespread use of this procedure, though mortality was approximately 10\% (Cooper 1953). Electrical coagulation procedures involving the globus pallidus, thalamus, and the ansa lenticularis (ansotomy) were performed with early stereotaxic procedures (Spiegel and Wycis 1954). Hassler and Reichert focused more directly on the ventrolateral nucleus of the thalamus, also referred to as the Ventral Oralis Anterior (Voa) nucleus (Hassler 1955; Reichert 1962). All these reports were hampered by the lack of involvement by medical neurologists with resultant concerns of incomplete reporting, lack of long-term follow-up and potential minimalization of morbidity. Further, the role of surgery was eclipsed by the advent of levodopa in the 1960s, so that a long hiatus occurred when surgery was not extensively used in Parkinson's disease. During this time, however, more advanced surgical techniques were developed, and these innovations would be later applied to Parkinson's disease patients near the end of the twentieth century. Such treatments date to the contemporary period and include pallidotomy, subthalamic nucleus ablation, deep brain stimulation to thalamus, pallidum and subthalamic, and various transplantation procedures. Most recent are the developments of gene-based therapies that have entered clinical trials.

\section{Placebo Therapy}

The relationships between dopamine release and positive motivation, novelty seeking behaviors, and attention have allowed researchers to understand the long-acknowledged placebo impact on Parkinson's disease. The Charcot letters cited above suggest that Charcot too understood clearly the importance of his presence and command over the patient's well-being. As anchored as he remained in neuroanatomical concepts through the end of his career, Charcot's last monograph was titled "Faith Cure" and dealt with the profound improvements that some patients with neurological disease experienced through nontraditional therapies (Charcot 1892b). Placebo-controlled trials have become standard in Parkinson's disease, even in the surgical arena, mainly because a large percentage of patients on placebo treatment experience objective improvement in parkinsonism (Goetz et al. 2008). The facilitation of 
striatal dopaminergic activity in these settings has been shown by neuroimaging techniques (de la Fuente-Fernandez et al. 2001). The funding of federal grants for the specific study of placebo effects in Parkinson's disease is, in itself, of historical significance (Goetz et al. 2008).

\section{CONCLUDING REMARKS}

Historical documents on Parkinson's disease and descriptions that evoke Parkinsonism from eras prior to the first full medical delineation of the disease provide a continuing source of potential neurological insights. As only one example, summarized in a review of traditional and complementary therapies for Parkinson's disease (Manyam and Sánchez-Ramos 1999), in 1928, Lewin isolated an alkaloid from the Banisteriopsis caapi vine used in ceremonial medicine among Amazonian tribes. He provided purified banisterine to his colleague, Beringer, who tested it on patients with Parkinson's disease with reported marked benefit. The data were presented to the Berlin Medical Association along with a film documenting the changes in rigidity, bradykinesia, and gait impairment. Though this agent was not pursued further, the example underscores the potential lessons from careful reading of traditional medicine sources and the prospects for new discoveries based on older observations. Charcot's advocacy for vibratory therapy has been tested in a modern setting (Kapur et al. 2011), but Gowers' encouraged use of Cannabis has yet to be systematically evaluated with strong clinical trial methodology. Numerous other therapies have suggestive roles in Parkinson's disease but have not been rigorously tested, including specific forms of physical exercise, massage therapy, and relaxation techniques. The active participation of the Parkinsonian subject in these treatments complicates a controlled study design, but these interventions scientifically deserve to be tested with the same rigor as new pharmacological or surgical treatments. In the continuing search for therapies to ameliorate current disability and to slow the natural deterioration that is implicit to Parkinson's disease today, the guiding words of Charcot remain modern and applicable: "If you do not have a proven treatment for certain illnesses, bide your time, do what you can, but do not harm your patients" (Charcot 1888b).

\section{ACKNOWLEDGMENTS}

Dr. Goetz acknowledges the Parkinson's Disease Foundation that supports the Rush University Medical Center Parkinson's Disease and Movement Disorder Program with an annual grant.

\section{REFERENCES}

Adams RD, van Bogaert L, Vander Eecken H. 1964. Striatonigral degeneration. J Neuropathol Exp Neurol 23: $584-$ 608.

Babinski J. 1921. Kinésie parodoxale. Rev Neurol 37: 12661270.

Barbeau A. 1969. L-Dopa therapy in Parkinson's disease. Can Med Assoc J 101: 59-68.

Bertler Å, Rosengren E. 1959. Occurrence and distribution of dopamine in brain and other tissues. Experientia 15: $10-11$.

Birkmayer W, Hornykiewicz O. 1961. Der L-Dioxyphenylalanin-Effekt bei der Parkinson-Akinese. Wien Klin Wschr 73: 787-788.

Brissaud E. 1925. Leçons sur les maladies nerveuses. Masson, Paris.

Bruyn GW, Bots GT, Staal A. 1964. Familial bilateral vascular calcification in the central nervous system. Psychiatr Neurol Neurochir 67: 342-376.

Bucy PC, Case JT. 1939. Tremor: Physiologic mechanism and abolition by surgical means. Arch Neurol Psychiatr 41: $721-746$.

Carlsson A, Lindqvist M, Magnusson T, Waldeck B. 1958. On the presence of 3-hydroxytyramine in brain. Science 127: 471 .

Charcot J-M. 1872. De la paralysie agitante. In Oeuvres Complètes $(t 1)$ Leçons sur les maladies du système nerveux, pp. 155-188. A Delahaye, Paris. [In English: Charcot J-M. 1877. On Parkinson's disease. In Lectures on diseases of the nervous system delivered at the Salpetrière (transl. Sigerson G), pp. 129-156. New Sydenham Society, London.]

Charcot J-M. 1888a. Leçons du Mardi: Policlinique de la Salpêtrière, 1887-1888. Bureaux du Progrès Médical, Paris. Lesson of June 12, 1888.

Charcot J-M. 1888b. Leçons du Mardi: Policlinique de la Salpêtrière, 1887-1888. Bureaux du Progrès Médical, Paris. Lesson of November 15, 1887.

Charcot J-M. 1892a. La médicine vibratoire: Application des vibrations rapides et continues a traitement de quelques maladies du système nerveux. Prog Méd 16: 149-151. [In English: Charcot J-M. 1892. Vibratory therapeutics: The application of rapid and continuous vibrations to the treatment of certain diseases of the nervous system. J Nerv Ment Dis 19: 880-886.] 
C.G. Goetz

Charcot J-M. 1892b. Faith-cure. New Rev 11: 244-262 [In French: Charcot J-M. 1892. La foi qui guérit. Rev Hebdomadaire 5: 112-132.]

Cooper IS. 1953. Ligation of the anterior choroidal artery for involuntary movements of parkinsonism. Psychiat Quart 27: 317-319.

Cotzias GC, Papavasiliou PS, Gellene R. 1969. Modification of parkinsonism: Chronic treatment with L-dopa. N Engl J Med 280: 337-345.

de Goncourt E, de Goncourt D. 1887-1889. Journal: Mémoires de la vie littéraire, Vol. 3. Flammarion, Paris.

de la Fuente-Fernandez R, Ruth TJ, Sossi V. 2001. Expectation and dopamine release: Mechanism of the placebo effect in Parkinson's disease. Science 293: 1164-1166.

Dutil A. 1889. Sur un cas de paralysie agitante à forme hemiplégique avec attitude anormale de la tête et du tronc (extension). Nouvelle Iconographie de la Salpêtrière 2: 165-169.

Ehringer H, Hornykiewicz O. 1960. Verteilung von noradrenalin and dopamin im gehirn des menschen und ihr verhalten bei erkrankungen des extrapyramidalen systems. Klin Wschr 38: 1126-1239.

Foix MC, Nicolesco J. 1925. Les noyaux gris centraux et la région mesencéphalo-sous-optique. Masson, Paris.

Goetz CG. 1987. Charcot the clinician: The Tuesday lessons. Raven Press, New York.

Goetz CG. 1996. An early photographic case of probable progressive supranuclear palsy. Mov Disord 11: 617-618.

Goetz CG, Bonduelle M, Gelfand T. 1995. Charcot: Constructing neurology. Oxford University Press, New York.

Goetz CG, Wuu J, McDermott MP, Adler CH, Fahn S, Freed CR, Hauser RA, Olanow WC, Shoulson I, Tandon PK, et al. 2008. Placebo response in Parkinson's disease: Comparisons among 11 trials covering medical and surgical interventions. Mov Disord 15: 690-699.

Gowers WR. 1888. A manual of diseases of the nervous system. $\mathrm{J}$ and A Churchill, London.

Gowers WR. 1899. Paralysis agitans. In A system of medicine (ed. Allbutt A, Rolleston T), pp. 156-178. Macmillan, London.

Greenfield JG, Bosanquet FD. 1953. The brain-stem lesions in Parkinsonism. J Neurol Neurosurg Psychiatry 16: 213 226.

Hassler R. 1955. The influence of stimulations and coagulations in the human thalamus on the tremor at rest and its physiopathologic mechanism. Proc Second Intl Congr Neuropath 1: 637-642.

Hoehn MM, Yahr MD. 1967. Parkinsonism: Onset, progression and mortality. Neurology 17: 427-442.

Hornykiewicz O. 2002. Dopamine miracle: From brain homogenate to dopamine replacement. Mov Disord 17: 501-508.

Horsley V, Clarke RH. 1908. The structure and function of the cerebellum examined by a new method. Brain 31: 45-124.

Hunt JR. 1917. Progressive atrophy of the globus pallidus. Brain 40: $58-148$

Jankovic J. 1984. Progressive supranuclear palsy. Neurol Clin 2: $473-486$.
Kapur SS, Stebbins GT, Goetz CG. 2011. Vibration therapy and Parkinson's disease. Mov Disord 26 (Suppl 2): S132.

Klemme RM. 1940. Surgical treatment of dystonia, paralysis agitans and athetosis. Arch Neurol Psychiatry 44: 926.

Langston JW, Ballard P, Tetrud JW, Irwin I. 1983. Chronic parkinsonism in humans due to a product of Meperidine-Analog Synthesis. Science 219: 979-980.

Manyam BV. 1990. Paralysis agitans and levodopa in "Ayurveda": Ancient Indian medical treatise. Mov Disord 5: $47-48$.

Manyam BV, Sánchez-Ramos JR. 1999. Traditional and complementary therapies in Parkinson's disease. $A d v$ Neurol 80: $565-574$.

Meyers R. 1940. The modification of alternating tremors, rigidity and festination by surgery of the basal ganglia. Proc Assoc Nerv Ment Dis 21: 602-665.

Mitchell SW. 1908. Rest and psychotherapy. JAMA 50: 2034.

Muenter MD, Whisnant JP. 1968. Basal ganglia calcification, hypoparathyroidism, and extrapyramidal motor manifestations. Neurology 18: 1075-1083.

Onuaguluchi G. 1968. Drug treatment of parkinsonism and its assessment. In Handbook of clinical neurology (ed. Vinken PJ, Bruyn GW), Vol. 6, pp. 218-226. NorthHolland, Amsterdam.

Ordenstein L. 1972. Sur la paralysie agitante et la sclérose en plaque généralisée. E Martinet, Paris.

Parkinson J. 1817. An essay on the shaking palsy. Whittingham and Rowland for Sherwood, Needly and Jones, London.

Reichert T. 1962. Long term follow-up of results of stereotaxic treatment in extrapyramidal disorders. Confin Neurol 22: 336-363.

Richer P, Meige H. 1895. Etude morphologique sur la maladie de Parkinson. Nouvelle Iconographie de la Salpêtrière 8: $361-371$.

Romberg M. 1846. Lehrbuch der nervenkrankheiten des menschen. A Duncker, Berlin. [In English: Romberg M. 1853. A manual of the nervous diseases of man (trans. Sieveking EH). New Sydenham Society, London.

Sano I, Gamo T, Kakimoto Y. 1959. Distribution of catechol compounds in human brain. Biochim Biophys Acta 32: $586-587$.

Sauvages de la Croix FB de. 1763. Nosologia methodica Amstelodami: Sumptibus Fratrum de Tournes.

Schwab RS, England AC, Poskanzer DC. 1969. Amantadine in the treatment of Parkinson's disease. JAMA 208: $1168-1170$.

Spiegel EA, Wycis HT. 1954. Ansotomy in paralysis agitans. Arch Neurol Psychiatry 71: 598-614.

Steck H. 1954. Le syndrôme extra-pyramidale et di-encéphalique au cours des traitments au Largactil et au Serpasil. Ann Méd-Psychchiatr 112: 737-743.

Sylvius de la Boë F. 1680. Opera Medica. Danielem Elsevirium et Abrahamum Wolfgang, Amsterdam.

Trétiakoff C. 1921. Contribution à l'étude de l'anatomie du locus niger. Rev Neurol 37: 592-608.

Tyler K. 1992. A history of Parkinson's disease. In Handbook of Parkinson's disease (ed. Koller WC), pp. 1-34. Marcel Dekker, New York. 
van Bogaert L. 1930. Contribution clinique et anatomique à l'etude de la paralysie agitante juvenile primitive. Rev Neurol 2: 315-326.

von Economo C. 1919. Grippe-encephalitis und Encephalitis lethargic. Wiener klinishe Wochenschrift 32: $393-$ 396.

Westphal ACO. 1883. Über eine dem Bilde der cerebrospinalen grauen Degeneration ähnliche Erkrankung des centralen Nervensystems ohne anatomischen Befund, nebst einigen Bemerkungen über paradoxe Contraction. Arch Psychiatr Nervenkr 14: 87-95, 767-773.

Willige V. 1911. Ueber Paralysis Agiotans in Jugendlichen alter. Ztschr ges Neurol u Psychiatt 7: 263-265.

Yahr MD, Duvoisin RC, Schear MJ. 1969. Treatment of parkinsonism with levodopa. Arch Neurol 21: 343-354.

Zhang Z-X, Dong Z-H, Román GC. 2006. Early descriptions of Parkinson's disease in ancient China. Arch Neurol 63: $782-784$. 


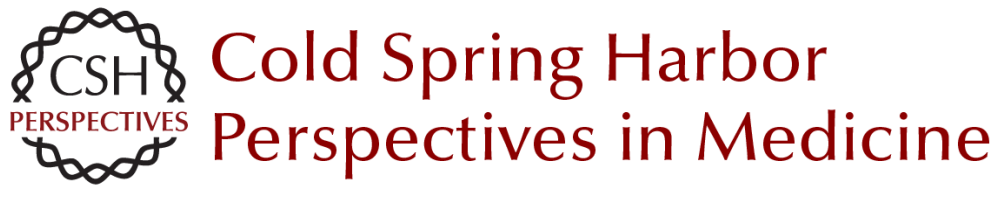

\title{
The History of Parkinson's Disease: Early Clinical Descriptions and Neurological Therapies
}

\author{
Christopher G. Goetz
}

Cold Spring Harb Perspect Med 2011; doi: 10.1101/cshperspect.a008862

\section{Subject Collection Parkinson's Disease}

Functional Neuroanatomy of the Basal Ganglia José L. Lanciego, Natasha Luquin and José A. Obeso

Animal Models of Parkinson's Disease: Vertebrate Genetics Yunjong Lee, Valina L. Dawson and Ted M. Dawson

Innate Inflammation in Parkinson's Disease V. Hugh Perry

Parkinson's Disease and Parkinsonism:

Neuropathology Dennis W. Dickson

Physiological Phenotype and Vulnerability in Parkinson's Disease D. James Surmeier, Jaime N. Guzman, Javier Sanchez, et al.

Clinical Approach to Parkinson's Disease: Features, Diagnosis, and Principles of Management João Massano and Kailash P. Bhatia

The Role of Autophagy in Parkinson's Disease Melinda A. Lynch-Day, Kai Mao, Ke Wang, et al.

Disruption of Protein Quality Control in Parkinson's Disease Casey Cook, Caroline Stetler and Leonard Petrucelli
Drosophila as a Model to Study Mitochondrial

Dysfunction in Parkinson's Disease Ming Guo

Parkinsonism Due to Mutations in PINK1, Parkin, and DJ-1 and Oxidative Stress and Mitochondrial Pathways Mark R. Cookson

Programmed Cell Death in Parkinson's Disease Katerina Venderova and David S. Park

Genomics and Bioinformatics of Parkinson's Disease

Sonja W. Scholz, Tim Mhyre, Habtom Ressom, et al.

Motor Control Abnormalities in Parkinson's

Disease

Pietro Mazzoni, Britne Shabbott and Juan Camilo Cortés

Parkinson's Disease: Gene Therapies Philippe G. Coune, Bernard L. Schneider and Patrick Aebischer

Functional Neuroimaging in Parkinson's Disease Martin Niethammer, Andrew Feigin and David Eidelberg

Leucine-Rich Repeat Kinase 2 for Beginners: Six

Key Questions Lauren R. Kett and William T. Dauer

For additional articles in this collection, see http://perspectivesinmedicine.cshlp.org/cgi/collection/ 